\title{
Correction to: Solochrome cyanine: A histological stain for cobalt- chromium wear particles in metal-on-metal periprosthetic tissues
}

\author{
I. Papadimitriou-Olivgeri ${ }^{1}$ J. M. Brown ${ }^{1}$ - A. F. R. Kilpatrick ${ }^{2}$ H. S. Gill ${ }^{3}$ - N. A. Athanasou ${ }^{1}$
}

Published online: 25 September 2019

(c) Springer Science+Business Media, LLC, part of Springer Nature 2019

\section{Correction to: Journal of Materials Science:}

Materials in Medicine (2019) 30:103

https://doi.org/10.1007/s10856-019-6304-0

The original version of this article unfortunately contained a mistake. The title of the article was incorrect in the PDF version of this article. It should read as "Solochrome cyanine: A histological stain for cobalt-chromium wear particles in metal-on-metal periprosthetic tissues". The original article has been corrected.

The original article can be found online at https://doi.org/10.1007/ s10856-019-6304-0.

N. A. Athanasou

nick.athanasou@ndorms.ox.ac.uk

1 Department of Histopathology, NDORMS, University of Oxford, Nuffield Orthopaedic Centre, Oxford OX3 7HE, UK

2 Chemistry Research Laboratory, Mansfield Road, Oxford OX1 3TA, UK

3 Department of Mechanical Engineering, University of Bath, Bath BA2 7AY, UK 